\title{
Prevalence and Etiology of Pediatric Maxillofacial Fractures in a Group of Yemeni Children and Adolescents
}

\author{
Nashwan Hamid Al-Tairi*, Jabr Atiq Al-Radom \\ Department of Oral and Maxillofacial Surgery, Faculty of Dentistry, Thamar University, Dhamar, Yemen \\ Email: *nashwanh9@gmail.com
}

How to cite this paper: Al-Tairi, N.H. and Al-Radom, J.A. (2021) Prevalence and Etiology of Pediatric Maxillofacial Fractures in a Group of Yemeni Children and Adolescents. Open Journal of Stomatology, 11, 179-187. https://doi.org/10.4236/ojst.2021.115015

Received: December 21, 2020

Accepted: May 7, 2021

Published: May 10, 2021

Copyright $\odot 2021$ by author(s) and Scientific Research Publishing Inc. This work is licensed under the Creative Commons Attribution International License (CC BY 4.0).

http://creativecommons.org/licenses/by/4.0/

\section{(c) (i) Open Access}

\begin{abstract}
Although maxillofacial fractures are not as common in children as in adults, trauma is still the leading cause of morbidity and mortality in the pediatric population worldwide. The aim of this study was to review the pattern and prevalence of pediatric maxillofacial fractures in a sample of the Yemeni population aged 18 years and below. A retrospective analysis of patient records and radiographs was conducted for the 4 year period between June 2016 and October 2020. A total of 71 patients had 87 fractures divided into three age groups, i.e., preschool group (0 - 6 years), primary school group ( 7 - 12 years) and teenage group (13 - 18 years). The male to female ratio was $2.38: 1$ and the highest incidence occurred in the age group 13 to 18 years. The main etiological factor was road traffic accidents (RTA), however, falls were the primary etiology in the preschool age group. We conclude that maxillofacial trauma in pediatric patients is associated mainly with RTA and fall and; the mandible is more affected than other maxillofacial structures with the condyle being the most frequently fractured mandibular site.
\end{abstract}

\section{Keywords}

Pediatric, Maxillofacial, Fracture, Trauma

\section{Introduction}

Pediatric maxillofacial fractures are uncommon compared with adults. The incidence of pediatric facial fractures ranged between $1 \%-15 \%$ of all facial fractures [1] [2] [3] The variations in the structural anatomy, the flexibility of the pediatric skeleton, the large quantities of facial soft tissues, and the lack of paranasal sinus pneumatization contribute to reduced frequency of pediatric frac- 
tures [4] [5] [6] [7] [8]. The protected environments under parental supervision also make them less likely to be exposed to major trauma as are adults [9] [10]

The etiology of maxillofacial injuries in children varies according to social, cultural, and environmental factors, however, the main causes worldwide are traffic accidents, falls, altercations, and sports-related accidents, while interpersonal violence is rare [1] [3] [11] [12]. Despite advancements in child safety, trauma remains the most common cause of pediatric morbidity and mortality [13]. A survey in the United Kingdom has shown that trauma remains the mean cause of morbidity and mortality in children and affects one in three annually [2] [14].

Studies in this age group have reported mandibular fractures to be the most common with condylar and para-symphyseal fractures are reported to be more frequent [15] [16] [17].

Epidemiological data on pediatric maxillofacial trauma is important as it has obvious implications for improving care by its use in clinical audit, service management, planning of future services, and effective targeting of preventive measures [18]. Social, cultural, and environmental factors vary from one country to another and influence the incidence and etiology of facial trauma [6] [7] [19]-[24].

To the best of our knowledge, there is no study so far evaluated the epidemiological data of pediatric maxillofacial fractures in Yemen. Therefore, our aim is to report the prevalence, socio-demographics, causes, and pattern of maxillofacial fractures in children and adolescents in a sample of the Yemeni population.

\section{Patients and Methods}

This was a retrospective study that included pediatric and adolescent patients with maxillofacial fractures. The protocol was approved by the ethics committee of the faculty of dentistry, Thamar University. We retrospectively examined the records of patients treated at three mean medical hospitals (Almusali, Lebanon and Alsaidah) in Dhamar city, Yemen, from June 2017 to October 2020. To be included in the study, patients had to be aged 18 years or less at the time of initial admission. They were assigned to three age groups, preschool ( 0 - 6 years), primary school ( 7 - 12 years), and teenage (13 - 18 years).

The patient records were reviewed, and data including gender, age, mechanism of injury, site of the fracture, and type of fracture were recorded. The mechanism of trauma included road traffic accidents (RTA), falls, and violence. The fractures were categorized into those of the mandible, maxillae, nasal bone, zygomatic bone, and orbital bone. The classifications of the fractures were based on conventional radiographic study and computed tomographic examinations. Sites of mandibular fractures included symphysis and parasymphysis, body, angle, ramus, and condyle.

\section{Statistical Analysis}

Data analyzed by using statistical software SPSS version 20 (SPSS Inc., Chicago, IL, USA). Chi-square test was performed and significance level set at $\mathrm{p}<0.05$. Descriptive analyses: proportions, percentages, and frequency distribution were 
performed.

\section{Results}

A total of 483 cases of oral and maxillofacial fracture were reviewed. Seventy-one were cases involving children and adolescents who are 18 years or younger giving a prevalence of $14.6 \%$. The age ranged from 3 years to 18 years with a mean of $12.1 \pm 4.9$. There were 50 boys $(70.4 \%)$ and 21 girls $(29.6 \%)$, in a ratio of 2.38:1.

The age group with the lowest proportion was that of children under 6 years of age, accountable for $18.3 \%$ of the cases, and the most frequent age range was that of patients between $13-18$ years of age, presenting $50.7 \%$ of the cases. The male-to-female ratio in patients aged 0 - 6 years was 2.2:1. This ratio decreased to 1.4:1 in patients who were $7-12$ years, while it increased in patients who were 13 - 18 years old to $3.5: 1$ (Table 1 ).

\subsection{Mechanism of Injury}

The primary mechanism of fractures was RTA (67.6\%), followed by falls (26.8\%) and then violence (5.6\%).

Mechanism of fractures was associated with patient age. Fall was the most common etiology in children aged $\leq 6$ years $(69.2 \%)$, while in patients aged $\geq 7$ years, the primary etiology was RTA. There was a significant difference between the $1^{\text {st }}$ and $3^{\text {rd }}$ age groups for RTA, fall, and violence $(\mathrm{P}<0.05)$ (Table 2).

\subsection{Location and Type of Fracture}

A total of 87 fractures were recorded. Isolated fractures were found in $63.4 \%$ of study patients while $36.6 \%$ of patients sustained multiple fractures. Mandibular

Table 1. Distribution of patients according to different age groups.

\begin{tabular}{ccccc}
\hline \multirow{2}{*}{ Age group } & \multicolumn{2}{c}{ Gender } & & total \\
\cline { 2 - 3 } & $9(18.0 \%)$ & $4(19.0 \%)$ & $13(18.3 \%)$ & M/F ratio \\
\hline $0-6$ years & $13(26.0 \%)$ & $9(42.9 \%)$ & $22(31.0 \%)$ & $1.4: 1$ \\
$7-12$ years & $28(56.0 \%)$ & $8(38.1 \%)$ & $36(50.7 \%)$ & $3.5: 1$ \\
\hline
\end{tabular}

Table 2. Frequency of etiology of facial fractures in relation to gender and age group.

\begin{tabular}{|c|c|c|c|c|c|c|c|}
\hline \multirow{2}{*}{$\begin{array}{l}\text { Cause of } \\
\text { trauma }\end{array}$} & \multicolumn{2}{|c|}{ Gender } & \multirow{2}{*}{ Total } & \multicolumn{3}{|c|}{ Age group } & \multirow{2}{*}{ Total } \\
\hline & male & female & & $0-6$ & $7-12$ & $13-18$ & \\
\hline RTA & $36(72.0 \%)$ & $12(57.1 \%)$ & $48(67.6 \%)$ & $4(30.8 \%)$ & $15(68.2 \%)$ & $29(80.6 \%)$ & $48(67.6 \%)$ \\
\hline Fall & $10(20.0 \%)$ & $9(42.9 \%)$ & $19(26.8 \%)$ & $9(69.2 \%)$ & $6(27.3 \%)$ & $4(11.1 \%)$ & $19(26.8 \%)$ \\
\hline violence & $4(8.0 \%)$ & $0(0.0 \%)$ & $4(5.6 \%)$ & $0(0.0 \%)$ & $1(4.5 \%)$ & $3(8.3 \%)$ & $4(5.6 \%)$ \\
\hline
\end{tabular}


fractures had the highest frequency of occurrence $55.2 \%$, followed by nasal fractures (18.4\%), zygoma (14.9\%), maxilla (8.0\%), and orbit (3.4\%) (Table 3). In mandible, 56 fractures in 45 patients were observed. The most common site of mandibular fractures was condyle (39.3\%), followed by symphysis and parasymphysis (35.7\%), angle (16.1\%), and body (8.9\%) (Table 4).

\section{Discussion}

Many of the unique features of pediatric facial trauma are directly related to the underdevelopment and continuing growth of the facial skeleton [8]. The variations seen in the types of facial injuries that occur between children and adults are related to the variations in the structural anatomy. As children age and their facial structure begin to grow downward and outward, their injury patterns begin to mirror those of adults [8] [25].

In this study $14.6 \%$ of the patients presenting with facial fractures were children. This figure is consistent with other studies from different parts of the world, where facial fractures in the pediatric population were reported to be less than $15 \%$ of all facial fractures [10] [18] [26] [27]. Hill, et al. [28] reported a higher rate (30\%) of maxillofacial injuries in children, probably because their study was done in a specialist trauma center with a high referral rate.

Previously published work showed a higher incidence rate of maxillofacial fractures in males, with male-to-female ratios ranging from 1.5:1 to 2.8:1 [11] [26] [29]-[34], n our study, the male-to-female ratio was $2.38: 1$, which was consistent with previous figures. Daniels, et al. [35] reported a male to female ratio of 16.6:1

Table 3. Distribution of facial fracture location according to gender and age group.

\begin{tabular}{cccccccc}
\hline \multirow{2}{*}{$\begin{array}{l}\text { Fracture } \\
\text { location }\end{array}$} & \multicolumn{2}{c}{ Gender } & Total & \multicolumn{3}{c}{ Age group } & Total \\
\cline { 2 - 3 } & male & female & & $0-6$ & $7-12$ & $13-18$ & \\
\hline Mandible & $31(50.8 \%)$ & $17(65.4 \%)$ & $48(55.2 \%)$ & $11(84.6 \%)$ & $14(53.8 \%)$ & $23(47.9 \%)$ & $48(55.2 \%)$ \\
Maxilla & $6(9.8 \%)$ & $1(3.8 \%)$ & $7(8.0 \%)$ & $0(0.0 \%)$ & $2(7.7 \%)$ & $5(10.4 \%)$ & $7(8.0 \%)$ \\
Nasal & $11(18.0 \%)$ & $5(19.2 \%)$ & $16(18.4 \%)$ & $2(15.4 \%)$ & $5(19.2 \%)$ & $9(18.8 \%)$ & $16(18.4 \%)$ \\
Zygoma & $10(16.4 \%)$ & $3(11.5 \%)$ & $13(14.9 \%)$ & $0(0.0 \%)$ & $4(15.4 \%)$ & $9(18.8 \%)$ & $13(14.9 \%)$ \\
orbital & $3(4.9 \%)$ & $0(0.0 \%)$ & $3(3.4 \%)$ & $0(0.0 \%)$ & $1(3.8 \%)$ & $2(4.2 \%)$ & $3(3.4 \%)$ \\
\hline
\end{tabular}

Table 4. Distribution of mandibular fractures according to gender and age group.

\begin{tabular}{|c|c|c|c|c|c|c|c|}
\hline \multirow{2}{*}{$\begin{array}{c}\text { Mandibular } \\
\text { fracture } \\
\text { location }\end{array}$} & \multicolumn{2}{|c|}{ Gender } & \multirow{2}{*}{ Total } & \multicolumn{3}{|c|}{ Age group } & \multirow{2}{*}{ Total } \\
\hline & male & female & & $0-6$ & $7-12$ & $13-18$ & \\
\hline Symphysis & $16(42.1 \%)$ & $4(22.2 \%)$ & $20(35.7 \%)$ & $3(27.3 \%)$ & $5(29.4 \%)$ & $12(42.9 \%)$ & $20(35.7 \%)$ \\
\hline Body & $3(7.9 \%)$ & $2(11.1 \%)$ & $5(8.9 \%)$ & $2(18.2 \%)$ & $1(5.9 \%)$ & $2(7.1 \%)$ & $5(8.9 \%)$ \\
\hline Angle & $7(18.4 \%)$ & $2(11.1 \%)$ & $9(16.1 \%)$ & $0(0 \%)$ & $4(23.5 \%)$ & $5(17.9 \%)$ & $9(16.1 \%)$ \\
\hline Condyle & $12(31.6 \%)$ & $10(55.6 \%)$ & $22(39.3 \%)$ & $6(54.5 \%)$ & $7(41.2 \%)$ & $9(32.1 \%)$ & $22(39.3 \%)$ \\
\hline Total & 38 (100\%) & $18(100 \%)$ & $56(100 \%)$ & $11(100 \%)$ & $17(100 \%)$ & $28(100 \%)$ & $56(100 \%)$ \\
\hline
\end{tabular}


which is extremely high. They attributed this high ratio rate to the local culture where females spend more time at home with little or no outdoor activities.

Published data from different studies on the etiology and incidence of maxillofacial fractures tend to vary from one country to another, perhaps because of the differences in social, cultural, and environmental factors [1] [30] [32] [33] [34] [36]. Our results showed an increase of maxillofacial fractures according to age, with a high frequency in the adolescent group. Similar findings were also presented in many studies in the world [24] [26] [32] [33] [35]. In contrast to the finding of the current study, other studies found the primary school age group to have the highest prevalence among other groups [36] [37] [38]. This contrast may be owing to the fact that they did not include patients older than 15 years in their studies.

It has been found that, despite individual variation in the reported prevalence that ranged from $30 \%$ to $70 \%$, RTA was the most common cause of pediatric maxillofacial fractures [14] [26] [31] [34] [35] [37] [39]. Other studies showed that falls were the most frequent cause of pediatric facial fractures [1] [11] [30] [36] [38]. It is worth mentioning that teenagers are not included in those studies that reported fall as the main trauma etiology. A study from South Africa [24], oddly, found that violence is still a leading cause of facial fractures in a group of patients less than 18 years of age. In the present study, RTA was responsible for $67.6 \%$ of facial fractures in all patients. Among individual age groups, fall was prevalent in preschool groups, while RTA was the most common etiology among school and teenage groups. These results could be related to bad unrepaired roads and also due to the rising number of teenagers who are working on motor bicycles.

Many studies [11] [14] [24] [29] [34] [38] [39] [40] showed that the mandible was the most commonly involved bone in facial fractures with an incidence range of $32 \%-89 \%$. This was also shown in our study; mandibular fractures were noted to account for $55.2 \%$ of pediatric facial fractures. Unexpected pattern of fractures found by Van As, et al. [41] in their study on a group of South African children where orbital fracture was the most common site of facial fractures.

The second most frequently fractured facial bone in our study was the nasal bone. Similarly, some studies [32] [33] supported this finding. In contrast to our results, Daniels, et al. [35] found maxilla to be the second most commonly affected bone. Notably, they excluded nasal bone fractures from their study.

In the present study, the condyle was the most frequently involved part of the mandible within preschool and primary school age groups with an incidence of $54.5 \%, 41.2 \%$ respectively. However, within the teenage group, the symphysis was the most commonly fractured site (42.9\%). Most of the published studies showed that condyle is the most frequently fractured part of the mandible [11] [26] [30] [31] [33] [36] [38] [39], While other studies [1] [34] [40] found that mandibular symphysis was the most commonly affected. These differences could be related to the degree of force, the direction and the point of application of the force and to the cross-sectional area of the agent or object struck [42] [43]. 
In conclusion, the findings of this study have shown that pediatric facial fractures constitute $14.6 \%$ of the total facial fractures. RTA was the principal cause of maxillofacial fractures and the peak incidence occurred in the teenage group (50.7\%). The predominant site of fracture was the mandible (55.2\%), in which $39.3 \%$ of the fractures were found in the condylar region.

The current study is limited by its retrospective nature which is an inherent weakness. Also, the sample size was limited to the local community so it may not represent the true situation in Yemen.

\section{Conflicts of Interest}

The authors declare no conflicts of interest regarding the publication of this paper.

\section{References}

[1] Tanaka, N., Uchide, N., Suzuki, K., Tashiro, T., Tomitsuka, K., Kimijima, Y. and Amagasa, T. (1993) Maxillofacial Fractures in Children. Journal of Cranio-Maxillofacial Surgery, 21, 289-293. https://doi.org/10.1016/S1010-5182(05)80349-X

[2] Haug, R.H. and Foss, J. (2000) Maxillofacial Injuries in the Pediatric Patient. Oral Surgery, Oral Medicine, Oral Pathology, Oral Radiology, and Endodontology, 90, 126-134. https://doi.org/10.1067/moe.2000.107974

[3] Subhashraj, K., Nandakumar, N. and Ravindran, C. (2007) Review of Maxillofacial Injuries in Chennai, India: A Study of 2748 Cases. British Journal of Oral and Maxillofacial Surgery, 45, 637-639. https://doi.org/10.1016/j.bjoms.2007.03.012

[4] Lim, C.A., Singh, Y.K., Portnof, J.E. and Blumberg, S.M. (2016) Pediatric Maxillofacial Trauma: A Review of 156 Patients. Journal of Oral and Maxillofacial Surgery, 74, 1420.e1-4. https://doi.org/10.1016/j.joms.2016.03.001

[5] Allred, L.J., Crantford, J.C., Reynolds, M.F. and David, L.R. (2015) Analysis of Pediatric Maxillofacial Fractures Requiring Operative Treatment: Characteristics, Management, and Outcomes. Journal of Craniofacial Surgery, 26, 2368-2374. https://doi.org/10.1097/SCS.0000000000002087

[6] Ferreira, P.C., Barbosa, J., Braga, J.M., Rodrigues, A., Silva, Á.C. and Amarante, J.M. (2016) Pediatric Facial Fractures: A Review of 2071 Fractures. Annals of Plastic Surgery, 77, 54-60. https://doi.org/10.1097/SAP.0000000000000346

[7] Singhal, R., Singh, V., Bhagol, A., Agrawal, A. and Kumar, P. (2013) Pediatric Maxillofacial Injuries-If a New Look Is Required? International Journal of Pediatric Otorhinolaryngology, 77, 1333-1336. https://doi.org/10.1016/j.ijporl.2013.05.028

[8] Boyette, J.R. (2014) Facial Fractures in Children. Otolaryngologic Clinics of North America, 47, 747-761. https://doi.org/10.1016/j.otc.2014.06.008

[9] Bales, C.R., Randall, P. and Lehr, H.B. (1972) Fractures of the Facial Bones in Children. Journal of Trauma and Acute Care Surgery, 12, 56-66. https://doi.org/10.1097/00005373-197201000-00007

[10] Vyas, R.M., Dickinson, B.P., Wasson, K.L., Roostaeian, J. and Bradley, J.P. (2008) Pediatric Facial Fractures: Current National Incidence, Distribution, and Health Care Resource Use. Journal of Craniofacial Surgery, 19, 339-349. https://doi.org/10.1097/SCS.0b013e31814fb5e3

[11] Oji, C. (1999) Jaw Fractures in Enugu, Nigeria, 1985-95. British Journal of Oral and Maxillofacial Surgery, 37, 106-109. https://doi.org/10.1054/bjom.1997.0083 
[12] Chidzonga, M. (1987) Facial Fractures in Children. Central African Journal of Medicine, 33, 274-277.

[13] Bustos Córdova, E., Cabrales Martínez, R.G., Cerón Rodríguez, M. and Naranjo López, M.Y. (2014) Epidemiology of Accidental Injuries in Children: Review of International and National Statistics. Boletín Médico del Hospital Infantil de México (English Edition), 71, 68-75.

[14] Gassner, R., Tuli, T., Hächl, O., Moreira, R. and Ulmer, H. (2004) Craniomaxillofacial Trauma in Children: A Review of 3,385 Cases with 6,060 Injuries in 10 Years. Journal of Oral and Maxillofacial Surgery, 62, 399-407. https://doi.org/10.1016/j.joms.2003.05.013

[15] Imahara, S.D., Hopper, R.A., Wang, J., Rivara, F.P. and Klein, M.B. (2008) Patterns and Outcomes of Pediatric Facial Fractures in the United States: A Survey of the National Trauma Data Bank. Journal of the American College of Surgeons, 207, 710-716. https://doi.org/10.1016/j.jamcollsurg.2008.06.333

[16] Shand, J. (2018) Paediatric Oral \& Maxillofacial Surgery. Australian Dental Journal, 63, S69-S78. https://doi.org/10.1111/adj.12592

[17] Thorén, H., Iizuka, T., Hallikainen, D. and Lindqvist, C. (1992) Different Patterns of Mandibular Fractures in Children. An Analysis of 220 Fractures in 157 Patients. Journal of Cranio-Maxillofacial Surgery, 20, 292-296. https://doi.org/10.1016/S1010-5182(05)80398-1

[18] Hogg, N.J., Stewart, T.C., Armstrong, J.E. and Girotti, M.J. (2000) Epidemiology of Maxillofacial Injuries at Trauma Hospitals in Ontario, Canada, between 1992 and 1997. Journal of Trauma and Acute Care Surgery, 49, 425-432.

https://doi.org/10.1097/00005373-200009000-00007

[19] Zimmermann, C., Troulis, M. and Kaban, L. (2005) Pediatric Facial Fractures: Recent Advances in Prevention, Diagnosis and Management. International Journal of Oral and Maxillofacial Surgery, 34, 823-833. https://doi.org/10.1016/j.ijom.2005.06.015

[20] Li, Z. and Li, Z.-B. (2008) Characteristic Changes of Pediatric Maxillofacial Fractures in China during the Past 20 Years. Journal of Oral and Maxillofacial Surgery, 66, 2239-2242. https://doi.org/10.1016/j.joms.2007.12.032

[21] Glazer, M., Joshua, B.Z., Woldenberg, Y. and Bodner, L. (2011) Mandibular Fractures in Children: Analysis of 61 Cases and Review of the Literature. International Journal of Pediatric Otorhinolaryngology, 75, 62-64. https://doi.org/10.1016/j.ijporl.2010.10.008

[22] Rahman, R.A., Ramli, R., Rahman, N.A., Hussaini, H.M., Idrus, S.M.A. and Hamid, A.L.A. (2007) Maxillofacial Trauma of Pediatric Patients in Malaysia: A Retrospective Study from 1999 to 2001 in Three Hospitals. International Journal of Pediatric Otorhinolaryngology, 71, 929-936. https://doi.org/10.1016/j.ijporl.2007.03.003

[23] Qing, B.Z., Zhao, Q.Z., Dan, C. and Yan, Z. (2013) Epidemiology of Maxillofacial Injury in Children under 15 Years of Age in Southern China. Oral Surgery, Oral Medicine, Oral Pathology and Oral Radiology, 115, 436-441.

https://doi.org/10.1016/j.0ooo.2012.04.026

[24] Bamjee, Y., Lownie, J., Cleaton-Jones, P.E. and Lownie, M. (1996) Maxillofacial Injuries in a Group of South Africans under 18 Years of Age. British Journal of Oral and Maxillofacial Surgery, 34, 298-302.

https://doi.org/10.1016/S0266-4356(96)90006-6

[25] Grunwaldt, L., Smith, D.M., Zuckerbraun, N.S., Naran, S., Rottgers, S.A., Bykowski, M., Kinsella, C., Cray, J., Vecchione, L. and Saladino, R.A. (2011) Pediatric Facial 
Fractures: Demographics, Injury Patterns, and Associated Injuries in 772 Consecutive Patients. Plastic and Reconstructive Surgery, 128, 1263-1271. https://doi.org/10.1097/PRS.0b013e318230c8cf

[26] Almahdi, H.M. and Higzi, M.A. (2016) Maxillofacial Fractures among Sudanese Children at Khartoum Dental Teaching Hospital. BMC Research Notes, 9, 120. https://doi.org/10.1186/s13104-016-1934-5

[27] Ogunlewe, M., James, O., Ladeinde, A.L. and Adeyemo, W.L. (2006) Pattern of Paediatric Maxillofacial Fractures in Lagos, Nigeria. International Journal of Paediatric Dentistry, 16, 358-362.

[28] Hill, C.M., Crosher, R.F., Carroll, M.J. and Mason, D.A. (1984) Facial Fractures-The Results of a Prospective Four-Year-Study. Journal of Maxillofacial Surgery, 12, 267-270. https://doi.org/10.1016/S0301-0503(84)80257-X

[29] Khan, S., Khan, Z., Hanif, S., Riaz, N. and Warraich, R. (2019) Patterns of Facial Fractures in Children. British Journal of Oral and Maxillofacial Surgery, 57, 1009-1013. https://doi.org/10.1016/j.bjoms.2019.08.020

[30] Zachariades, N., Papavassiliou, D. and Koumoura, F. (1990) Fractures of the Facial Skeleton in Children. Journal of Cranio-Maxillofacial Surgery, 18, 151-153. https://doi.org/10.1016/S1010-5182(05)80509-8

[31] Anderson, P. (1995) Fractures of the Facial Skeleton in Children. Injury, 26, 47-50. https://doi.org/10.1016/0020-1383(95)90552-9

[32] Wang, H., Song, G., Ren, W., Zhou, Y., Li, C., Ou, L., Liu, J. and Xiang, L. (2018) Traumatic Facial Fractures in Children and Adolescents. Journal of Craniofacial Surgery, 29, 1809-1812. https://doi.org/10.1097/SCS.0000000000004964

[33] Munante-Cárdenas, J.L., Olate, S., Asprino, L., de Albergaria Barbosa, J.R., de Moraes, M. and Moreira, R.W. (2011) Pattern and Treatment of Facial Trauma in Pediatric and Adolescent Patients. Journal of Craniofacial Surgery, 22, 1251-1255. https://doi.org/10.1097/SCS.0b013e31821c696c

[34] Gussack, G.S., Luterman, A., Powell, R.W., Rodgers, K. and Ramenofsky, M.L. (1987) Pediatric Maxillofacial Trauma: Unique Features in Diagnosis and Treatment. The Laryngoscope, 97, 925-930. https://doi.org/10.1288/00005537-198708000-00008

[35] Daniels, J.S., Albakry, I., Braimah, R.O. and Samara, M.I. (2020) Maxillofacial Bone Fractures in Children and Adolescents: Overview of 247 Cases in a Major Referral Hospital, Najran, Kingdom of Saudi Arabia. Craniomaxillofacial Trauma \& Reconstruction. https://doi.org/10.1177/1943387520952680

[36] Joshi, S.R., Saluja, H., Pendyala, G.S., Chaudhari, S., Mahindra, U. and Kini, Y. (2013) Pattern and Prevalence of Maxillofacial Fractures in Rural Children of Central Maharashtra, India. A Retrospective Study. Journal of Maxillofacial and Oral Surgery, 12, 307-311. https://doi.org/10.1007/s12663-012-0425-Z

[37] Daniel, O., Ngutor, V., Idemudia, A., Adetokunbo, A., Cornelius, I. and Akinwale, E. (2013) Pediatric Maxillofacial Injuries at a Nigerian Teaching Hospital: A ThreeYear Review. Nigerian Journal of Clinical Practice, 16, 149-154. https://doi.org/10.4103/1119-3077.110126

[38] Qudah, M.A. and Bataineh, A.B. (2002) A Retrospective Study of Selected Oral and Maxillofacial Fractures in a Group of Jordanian Children. Oral Surgery, Oral Medicine, Oral Pathology, Oral Radiology, and Endodontology, 94, 310-314. https://doi.org/10.1067/moe.2002.127406

[39] Posnick, J.C., Wells, M. and Pron, G.E. (1993) Pediatric Facial Farctures: Evolving Patterns of Treatment. Journal of Oral and Maxillofacial Surgery, 51, 836-844. 
https://doi.org/10.1016/S0278-2391(10)80098-9

[40] Zhou, W., An, J., He, Y. and Zhang, Y. (2020) Analysis of Pediatric Maxillofacial Trauma in North China: Epidemiology, Pattern, and Management. Injury, 51, 1561-1567. https://doi.org/10.1016/j.injury.2020.04.053

[41] Van As, A., Van Loghem, A., Biermans, B., Douglas, T., Wieselthaler, N. and Naidoo, S. (2006) Causes and Distribution of Facial Fractures in a Group of South African Children and the Value of Computed Tomography in Their Assessment. International Journal of Oral and Maxillofacial Surgery, 35, 903-906. https://doi.org/10.1016/j.ijom.2006.07.008

[42] Pappachan, B. and Alexander, M. (2012) Biomechanics of Cranio-Maxillofacial Trauma. Journal of Maxillofacial and Oral Surgery, 11, 224-230. https://doi.org/10.1007/s12663-011-0289-7

[43] Nahum, A.M. (1975) The Biomechanics of Maxillofacial Trauma. Clinics in Plastic Surgery, 2, 59-64. https://doi.org/10.1016/S0094-1298(20)30097-3 